\title{
Response to Pasireotide in an acromegaly patient with resistance to conventional medical treatment
}

Authors: Sonia Gaztambide Sáenz. María Dolores Moure Rodríguez. Pedro González Fernández.

\begin{tabular}{||l||}
\hline Success rates (normalization of \\
\hline IGF-1 levels)*: \\
\hline Transsphenoidal surgery 40-50\% \\
Octreotide 17-35\% \\
Pegvisomant 63\% \\
Cabergoline 21-30\% \\
Cabatznelson L. et al. Acromegaly: An Endocrine Society Clinical \\
Practice Guideline. J Clin Endocrinol Metab 2014/10/30
\end{tabular}

\begin{abstract}
"Pasireotide exerts its activity via binding to four of the five known somatostatin receptors (SSTR), specifically: SSTR 1, SSTR2, SSTR3, and SSTR5. Pasireotide is different from the currently marketed somatostatin receptor analogs in the pattern of SST receptor binding and in the affinity that it has for individual SST receptors." *FDA briefing document NDA 200677

Pasireotide was approved by the EMA and the FDA for its use in acromegaly on 2014. In Spain, it can be prescribed for compassionate use only.
\end{abstract}

\section{CLINICAL CASE}

Female with a diagnosis of acromegaly at 24 years. She had a $3 \mathrm{~cm}$ macroadenoma.

\section{Undergone treatments:}

-Transsphenoidal surgery and transfrontal surgery, both in 1993.

-Radiotherapy in 1993

-On medical treatment since 1993 without success. On Octreotide LAR $\mathbf{3 0}$ mg monthly + Cabergoline $2 \mathrm{mg} /$ week:

03/2008: IGF-1 $589 \mathrm{ng} / \mathrm{ml}, \mathrm{GH} 12.1 \mathrm{ng} / \mathrm{ml}$

-Change to Pegvisomant 15 mg/day: achieved normal IGF-llevels but caused severe lipohypertrophy.

An International Novartis Committee approved treatment on Pasireotide $40 \mathrm{mg}$ monthly starting on June 2012. Dose was increased to $60 \mathrm{mg}$ monthly on March 2013:

\begin{tabular}{|l|c|c|l|}
\hline & $\mathbf{0 6 / 2 0 1 2}$ & $\mathbf{0 9 / 2 0 1 2}$ & $\mathbf{0 8 / 2 0 1 4}$ \\
\hline GH (ng/mL) & 33,9 & 8 & 2,3 \\
\hline IGF-1 (ng/mL) & 661 & 709 & 261 \\
& $(101-267)$ & $(101-267)$ & $(94-252)$ \\
\hline
\end{tabular}

No joint pain after improvement of IGF-1 levels, ..... but diabetes mellitus

\section{CONCLUSION}

\begin{tabular}{|c|c|c|c|}
\hline & $06 / 2012$ & $11 / 2013$ & $12 / 2014$ \\
\hline FPG $(\mathrm{mg} / \mathrm{dl})$ & 91 & 145 & - \\
\hline HbA1c (\%) & 5.8 & 6.7 & 6.6 \\
\hline Treatment & None & $\begin{array}{l}\text { Metformin } \\
\text { (up to } 2550 \mathrm{mg} / \text { day) }\end{array}$ & $\begin{array}{l}\text { Metformin/Vildagliptin } \\
(2000 \mathrm{mg} / 100 \mathrm{mg} \text { ) }\end{array}$ \\
\hline
\end{tabular}

In this clinical case, Pasireotide LAR has achieved clinical improvement, IGFI control, GH safety values, and diabetes mellitus as a side effect 